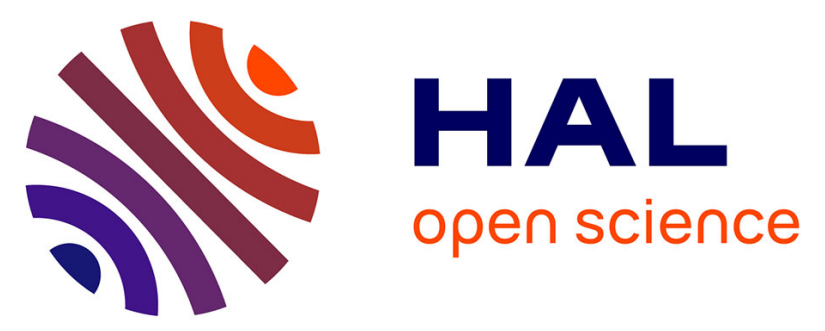

\title{
Chemotherapy for metastatic breast cancer. Comparison of clinical practice and cost of drugs in two cohorts of patients: 1994-1998 and 2003-2006
}

Guillaume Galy, Sana Intidhar Labidi-Galy, David Pérol, Thomas Bachelot, Isabelle Ray-Coquard, Olivier Tredan, Pierre Biron, Jean-François Latour, Jean-Yves Blay, Jean-Paul Guastalla, et al.

\section{To cite this version:}

Guillaume Galy, Sana Intidhar Labidi-Galy, David Pérol, Thomas Bachelot, Isabelle Ray-Coquard, et al.. Chemotherapy for metastatic breast cancer. Comparison of clinical practice and cost of drugs in two cohorts of patients: 1994-1998 and 2003-2006. Breast Cancer Research and Treatment, 2010, 128 (1), pp.187-195. 10.1007/s10549-010-1311-3 . hal-00615392

\section{HAL Id: hal-00615392 https://hal.science/hal-00615392}

Submitted on 19 Aug 2011

HAL is a multi-disciplinary open access archive for the deposit and dissemination of scientific research documents, whether they are published or not. The documents may come from teaching and research institutions in France or abroad, or from public or private research centers.
L'archive ouverte pluridisciplinaire HAL, est destinée au dépôt et à la diffusion de documents scientifiques de niveau recherche, publiés ou non, émanant des établissements d'enseignement et de recherche français ou étrangers, des laboratoires publics ou privés. 


\section{Original paper}

2 Chemotherapy for metastatic breast cancer. Comparison of clinical practice

3 and cost of drugs in two cohorts of patients: 1994-1998 and 2003-2006

\section{Authors}

5 Guillaume GALY ${ }^{145}$, Sana Intidhar LABIDI-GALY ${ }^{2}$, David PEROL ${ }^{3}$, Thomas BACHELOT ${ }^{2}$, Isabelle

6 RAY-COQUARD ${ }^{2}$, Olivier TREDAN ${ }^{2}$, Pierre BIRON ${ }^{2}$, Jean-François LATOUR ${ }^{1}$, Jean-Yves BLAY ${ }^{2}$, 7 Jean-Paul GUASTALLA ${ }^{2}$ and Bertrand FAVIER ${ }^{1}$.

8 Addresses

91 Department of Pharmacy, Centre Léon Bérard, 28 Rue Laennec Lyon 69008, France

$10{ }^{2}$ Department of Medical Oncology, Centre Léon Bérard, 28 Rue Laennec Lyon 69008, France

$11{ }^{3}$ Department of Biostatistics, Centre Léon Bérard, 28 Rue Laennec Lyon 69008, France

$12{ }^{4}$ Department of Pharmacy, Hôpital Edouard Herriot, 5 place d'Arsonval Lyon 69003, France

$13{ }^{5}$ Université Claude Bernard Lyon 1, 43 boulevard du 11 Novembre 1918 Villeurbanne 69622, France

14 Corresponding author

15 Guillaume GALY, Department of Pharmacy, Hôpital Edouard Herriot, 5 place d'Arsonval Lyon 69003,

16 France

$17 \quad$ Tel: +33472117385

$18 \quad$ Fax: +33472117411

19 E-mail: guillaume.galy@chu-lyon.fr

\section{Short title}

$21 \quad \mathrm{MBC}$ patients treated by chemotherapy 


\section{Abstract}

2 Purpose: Although new chemotherapeutic drugs for metastatic breast cancer (MBC)

3 have been approved over the past decade, it is unclear whether this has changed the

4 overall outcome of patients. This study assessed the clinical and economic impacts

5 of these drugs. Methods: We retrospectively studied MBC patients receiving

6 chemotherapy in our institution over two time periods, 1994-1998 and 2003-2006.

7 Patient characteristics and outcomes, and treatment characteristics and costs ( $€$,

8 2008) were compared. Results: Three hundred and one patients were identified, 149

9 patients in the first cohort and 152 in second one. The median number of lines was similar in the two cohorts (3 lines). The median costs of chemotherapy per patient

11 nearly doubled over time, from $6,272 €$ in the $1994-1998$ cohort to $13,035 €$ in the 2003-2006 cohort $(P<0.001)$. No survival difference was observed between the two

13 groups, with a 3-years survival rate estimated to $41 \%$ in the $1994-1998$ cohort and $1444 \%$ in the 2003-2006 cohort $(P=0.52)$. In multivariate analysis, prognostic factors associated with longer OS were single metastatic site (HR $\left.0.48 ; p<10^{-3}\right)$, bone metastases (HR=0.67; $P=0.007)$ and positive hormone receptors (HR 0.56; $P=0.0002)$. Conclusions: New chemotherapeutic agents induced a significant cost increase over time. The limited size and heterogeneity of our cohort do not allow any conclusion concerning their impact on survival.

\section{Key-words}

21 Metastatic breast cancer, chemotherapy, survival, costs, medico-economic study 


\section{Introduction}

2 Despite recent advances in early detection and treatment, breast cancer remains the

3 leading cause of death by cancer in women. At metastatic stages, there is no single

4 standard of care for the patients, as treatment plans require an individualized approach based on multiple factors including specific tumor biology, presence of visceral metastases, history of prior therapy and response, and patient preference.

7 Metastatic breast cancer (MBC) remains an incurable disease, and treatments are 8 aimed to improve patient quality of life and possibly to prolong survival without 9 excessive toxicity. The average survival time is no longer than 2 years [1].

10 Because of the chemosensitivity of the disease, the large majority of MBC patients 11 are candidates for chemotherapy, either upfront or after failure of hormonal 12 treatments. Over the last decade, new chemotherapy drugs, including capecitabine, 13 gemcitabine and liposomal doxorubicin, have been developed and approved in this 14 setting. In addition, targeted biologic agents, such as trastuzumab, bevacizumab and lapatinib, combined with traditional chemotherapies appear to offer new treatment opportunities. These molecules have been approved based on the results of hundreds of randomized trials comparing chemotherapy drugs, doses, combinations, sequences and durations. But it is important to note that only eight of these trials have shown improved survival in MBC patients [2, 3]. Furthermore, most published clinical trials have focused on first-line chemotherapies and few have evaluated the cost-efficacy of new drugs [4]. In the context of current health policy, with a majority of governments trying to limit the escalation of health care expenditures, such analysis may contribute to the on-going debate about the dissemination of innovative cancer drugs. 
1 In this retrospective study, we examined temporal trends in the use of

2 chemotherapeutic agents for the treatment of $\mathrm{MBC}$ in the context of clinical practice

3 and their costs. We also performed a study of the survival rates of MBC patients over

4 time.

6 Materials and Methods

\section{Patient selection}

8 The patients included in this retrospective study were selected among MBC patients

9 treated by chemotherapy at Léon Bérard Cancer Center (CLB), Lyon, France.

10 Inclusion criteria included histological or cytological evidence of breast cancer, but a

11 biopsy of the metastasis was not required. Based on the timing of the development

12 and dissemination of anti-MBC chemotherapeutic agents, we defined two time

13 cohorts, 1994-1998 (group 1) and 2003-2006 (group 2). Any patient diagnosed with

$14 \mathrm{MBC}$ (either primary tumor or first recurrence of distant metastases) and treated with chemotherapy could be included in these time cohorts. Patients in group 1 must have received their first cure of chemotherapy between January $1^{\text {st }} 1994$ and December $31^{\text {st }}$ 1998. Patients in group 2 must have received their first cure of chemotherapy between January 1, 2003 and December 31, 2006. Group 1 was used as the baseline comparator and corresponded to the introduction of taxanes (paclitaxel and docetaxel). Group 2 corresponded to the period when trastuzumab and capecitabine

21 became available. Prior endocrine therapy for metastatic disease was allowed. The institutional review board approved the acquisition and report of the data from these 23 patients.

24 The extent of metastatic involvement was determined by physical examination and routine imaging procedures including chest x-ray, liver ultrasound and bone scan 
1 before initiation of medical treatment. Information regarding date of diagnosis, patient

2 age, Scarff-Bloom and Richardson (SBR) grade and TNM stage [5] of the initial

3 tumor, performance status (PS), disease-free interval from initial diagnosis, number

4 and sites of metastases, hormone receptor (HR) status, HER-2 status and medical

5 treatments in the adjuvant and metastatic settings was obtained from original patient

6 records. A treatment was considered delivered when at least one dose of the drug

7 was received by the patient. The data were last updated in April 2008.

\section{Chemotherapy drugs}

The patients identified from the CLB breast cancer database were cross-referenced with the pharmacy database to collect information on the chemotherapeutic drugs used for their treatment. The pharmacy database records the date, the type and dose of all systemic agents administered in the hospital or at home and indications for their use in the treatment of a specific cancer in a given patient. For oral chemotherapy drugs purchased from local retail pharmacies, information was retrieved from original patient records and prescriptions. The line of chemotherapy (LOC) was defined as the interval from the date of the beginning of a treatment to the date of progression.

\section{Cost analysis}

The cost analysis was limited to the direct costs of chemotherapy drugs, thus 21 excluding the costs of drug preparation and administration, hospitalization and 22 transportation. The respective costs of chemotherapy agents were calculated from the beginning of treatment to death or end of the study. They were estimated in

24 Euros $(€, 2008)$ from the perspective of the French health care system. For 25 treatments administered in the hospital, we determined the exact number of 
1 milligrams per prescription and per patient, and then we multiplied this quantity by the

2 purchase price of each drug as nationally negotiated by the federation of French

3 cancer centers (FNCLCC) with which the CLB is affiliated. The treatments

4 administered at home were identified by examination of the follow-up records of the

5 patients. We determined the number of vials per prescription and per patient, and we

6 calculated the total cost of the treatment, assuming that every vial opened at home

7 was used (unused drug in opened vials was discarded). For oral chemotherapy drugs purchased from local pharmacies, the number of milligrams per prescription was determined and valued using prices fixed by the French public health authorities.

11 Statistical analysis

12 The characteristics of the patients were compared using Pearson's Chi-square test 13 (or Fisher's exact test, if necessary) and Student's $t$ test. Overall survival (OS) was defined as the time from diagnosis of metastasis to date of death or date of last follow-up for patients alive at last contact. Survival distributions were estimated by 16 the Kaplan-Meier method [6]. To evaluate the relationship between survival and 17 biological and/or clinical factors known to be relevant in MBC, all potential prognostic factors were included in univariate Cox proportional hazard regression models [7]. Candidate prognostic factors with a 0.05 level of significance in univariate analysis were then selected for inclusion in the multivariate analysis. Independent prognostic

21 variables of survival were identified by a Cox regression analysis using a backward 22 selection procedure to adjust the time cohort effect on patient's characteristics. All statistical analyses were performed using SAS software v.9.1 (Cary). All P values for two-tailed tests were considered significant when $\mathrm{P}<0.05$. 


\section{Results}

\section{Patient characteristics}

3 In total, 301 of 957 MBC patients of treated in our institution between 1994 and 2006

4 fulfilled the study criteria. Group 1 included 149 patients treated with chemotherapy

5 between 1994 and 1998, and group 2 included 152 patients treated between 2003

6 and 2006. The median follow-up for surviving patients was 3.87 years for the entire

7 cohort. Patient characteristics are listed in table 1. Overall, missing data were more

8 frequent in group 1. Patient characteristics did not statistically differ between groups,

9 except for age; patients of group 1 were younger than those of group 2. HR and HER-2 status were more frequently known in group 2. All patients of group 1 with

11 positive HR status received adjuvant hormone therapy, compared to only 64 patients (53.8\%) in group $2(P<0.001)$. Similarly, a greater proportion of patients in group 1 received hormone therapy for MBC (table 1) and this did not correlate with HR status.

14 Thus, 27 patients (81\%) with negative HR status received hormone therapy in group 1 , compared to only 12 patients $(21.4 \%)$ in group $2(P<0.001)$. The majority of patients from both groups received adjuvant chemotherapy, in 17 particular anthracyclines (Table 1). Only one patient from group 1 received taxanes in the adjuvant setting, compared to 18 patients $(15.1 \%)$ from group $2(p<0.001)$.

\section{Chemotherapy drugs administered for MBC}

21 The various chemotherapeutic agents used for the treatment of $M B C$ in the patients of the two time groups are outlined in table 2. Overall, there was no significant difference between groups in the median number of LOC $(n=3)$. There was a trend

24 toward a reduction in the use of anthracyclines over time. The quasi-totality of group 
1 compared to only $50 \%$ of group 2 patients. The lower use of anthracyclines in the

2 metastatic setting in group 2 was correlated with an increased use in the adjuvant

3 setting. Taxanes, trastuzumab and capecitabine were more frequently administered

4 to patients from the later time cohort. The majority of patients in group 2 received 5 taxanes $(84.9 \%)$, compared to $71.8 \%$ in group $1(P<0.01)$. Most patients in group 2 6 received taxanes in first line $(67.8 \%)$, compared to only $16.8 \%$ in group $1(p<0.001)$.

7 Trastuzumab was administered to all HER-2 positive patients from either group. But, 8 as HER-2 status was more frequently known in group 2, the number of patients 9 treated with trastuzumab was also much higher $(n=38)$ than in group $1(n=3)(T a b l e$ 2). Capecitabine was administered to $69 \%$ patients in group 2, compared to only $4.7 \%$ in group $1(P<0.001)$. Finally, 27 patients $(18.1 \%)$ of group 1 received highdose chemotherapy with stem cell transplantation (HDCSCT) and their median age was 37 years, whereas none of group 2 patients received HDCSCT.

All patients of the entire cohort received at least one cure of chemotherapy in the hospital. We observed a significant increase in the use of oral chemotherapy $(71.7 \%$ vs. $9.3 \% ; P<0.001)$ and systemic treatments at home $(32.2 \%$ vs. $2 \% ; P<0.001)$ over 17 time.

\section{Costs of chemotherapy drugs}

Not surprisingly, the total costs of chemotherapy nearly tripled over time. The overall costs of chemotherapy drugs for the entire cohort $(n=301)$ were estimated to be $5,209,771 €$, breaking down into $1,321,023 €$ for group 1 and $3,848,748 €$ for group 2. Thus, the median costs of chemotherapy drugs per patient increased from $6,272 €$ in group 1 to $13,035 €$ in group $2(P<0.001$; Table 4$)$. Up to progression, the median cost of metastatic breast cancer chemotherapy per 
1 patient and per year was $3,167 €$. It appeared to be higher in group $2(4,864 €)$ than

2 in group $1(2,273 €)$. As regards costs according to the LOC, the median cost of a

3 LOC was significantly higher in group $2(3,306 €)$ than in group $1(1,005 € ; P<0.001)$

4 (table 5).

5 Trastuzumab, docetaxel and paclitaxel were responsible for $66.7 \%$ of the total costs

6 of chemotherapy (Table 6). As expected, trastuzumab was the most expensive drug,

7 with a total of $1,800,007 €$, corresponding to $36.35 \%$ of the overall costs. With only

843 patients treated with trastuzumab in the entire cohort, the median cost per patient was $43,721 €$. The second most expensive molecule was docetaxel, with a total cost of $1,193,386 €$, corresponding to $22.9 \%$ of the total expenditures. The median cost of

11 docetaxel per patient was $6,521 €$. The third most expensive molecule was paclitaxel, with a total cost of $402,163 €$, corresponding to $7.7 \%$ of the total expenditures. The median cost of paclitaxel per patient was $4,278 €$.

\section{Survival of metastatic breast cancer patients treated by chemotherapy}

The median OS of the entire cohort was 2.75 years. The survival of MBC patients treated by chemotherapy did not change between the two cohorts (Figure 1A), with a 3-years OS rate estimated to $41 \%$ in the $1994-1998$ group and $44 \%$ in the $2003-2006$ group ( $P=0.52)$. Interestingly, we observed higher 5 -years survival rate in the second group (28\%) in comparison to the first one (16\%). Most of long surviving patients (> 5

21 years) in group 2 had hormone receptor positive tumors (73\%) and only two of them were HER-2 positive.

23 Univariate analysis of survival showed that the presence of $\mathrm{HR}$, a progression-free 24 interval $>2$ years, bone metastases and the administration of anthracyclines in first 25 line were associated with improved OS. In contrast, multiple metastases, soft tissue 
1 metastases, visceral metastases and performance status $>1$ were associated with 2 poor outcome (Table 3).

3 All patients with a positive HER-2 status $(n=41)$ received at least one line of

4 chemotherapy with trastuzumab used alone or combined with other drugs.

5 Interestingly, for patients with known HER-2 status ( $n=131)$, positivity was not

6 associated with worse survival ( $\mathrm{HR}=0.99, P=0.99$; Figure 2$)$. When only patients with

7 HR-positive tumors were considered $(n=172)$, the median OS was 3.15 years in

8 patients treated by chemotherapy between 2003 and 2006 and 2.54 years for those

9 treated between 1994 and 1998, but this difference was not statistically significant

$10(P=0.13$, Figure 3). As expected, a multivariate analysis adjusted on the patient

11 cohort showed that single metastatic site, bone metastases and HR were prognostic

12 factors for survival (Table 4).

13

14 


\section{Discussion}

2 Although clinical trials suggest that some advances have been made in the

3 management of MBC over the last two decades, it is not clear whether the survival of

4 these patients has improved in the context of daily practice. The major new

5 chemotherapy drugs were approved after 1994 and this date became a turning point

6 in cancer treatment. One of the objectives of our work was to study the evolution of

7 clinical practice in the treatment of MBC with chemotherapy during the last 15 years.

8 The first period (1994-1998) was chosen because it corresponds to the introduction

9 of taxanes in MBC.; paclitaxel was approved in France in 1994 and docetaxel in 1998. The second period (2003-2006) corresponds to the routine use of trastuzumab

11 and capecitabine, respectively approved in 2000 and 2002.

12 Patient's characteristics were not balanced in terms of age,

13 hormonal receptor status, HER-2 status and prior exposure to major

14 chemotherapeutic agents. Age difference is probably due to two principal causes.

15 First, the majority of old patients (older than 70 years) with MBC did not receive chemotherapy in the early 1990's because of the poor tolerability of available drugs 17 and the lack of supportive therapies. Most of these patients received hormone

18 therapies when indicated or palliative care. Second, in the 1990's, several clinical 19 trials testing HDCSCT were ongoing at the Centre Léon Bérard [8-10] and these 20 trials included only young patients (younger than 50 years). In our study, 27 patients 21 treated in group 1 received HDCSCT and their median age was 37 years.

22 HER-2 status was virtually unknown in the quasi-totality of the first group patients. 23 This analysis was generalized in the early 2000's with the generalization of 24 administration of trastuzumab to patients with positive HER-2 status. Similarly, hormone receptors (HR) status was more frequently known in group 2 than group 1 
1 whereas hormone therapies in the metastatic setting was prescribed to the majority

2 of patients of group 1, including some patients with negative HR. Until the end of the

3 1990's, hormone therapies could be administered to patients independently of HR

4 status [11]. The publication of a meta-analysis of clinical trials evaluating tamoxifen

5 [12] showed that positive HR is a predictive factor of response and changed clinical

6 practice.

7 Recent studies have investigated the costs of expensive drugs like trastuzumab [13-

815 ] and taxanes [16] or the total costs of chemotherapy [17] but, to our knowledge,

9 this is the first study describing the evolution of expenditures associated with all the

10 chemotherapy drugs prescribed in the context of daily clinical practice. Our study was

11 motivated by the fact that the costs of chemotherapeutic drugs have one of the

12 highest growth rates. In France, the French drug agency (AFSSAPS) estimated this

13 increase to be $23 \%$ per year in 2006 [18]. Overall, we observed an increase in the

14 administration of expensive drugs such as trastuzumab, taxanes and capecitabine, and a significant reduction in the administration of "old drugs", i.e. anthracyclines and

16 vinorelbine, to MBC patients. Consequently, the total costs of chemotherapy nearly

17 tripled while the median number of lines of chemotherapy remained stable. This increase in costs was mainly due to the two molecules described above, trastuzumab and docetaxel, which were responsible for more than half of expenditures. Our observations are in accordance with those reported by the French drug agency since

21 these two molecules were the most important cost drivers for hospital pharmacies in 222006 in France [18]. Although trastuzumab is responsible for $36 \%$ of the total costs of chemotherapy, in our cohort it beneficially altered the natural history of women with HER-2 positive MBC by leveling out outcome differences with women with HER-2 negative disease. 
1 Our study has revealed no significant difference in overall survival rate at 3 years

2 between the two periods of time. Nevertheless, it is important to note that this

3 survival was longer than reported in most published series $[19,20]$. Recent

4 retrospective studies have shown a trend toward improved survival in MBC patients

5 [19-22] but none has clearly demonstrated a relationship with new chemotherapeutic

6 drugs. Herein, we observed a tendency toward increased survival rate at 5 years in

7 group 2 patients' and most of these long-surviving patients had hormone positive

8 tumors, suggesting a benefit from new hormonal therapies.

9 Several hypotheses could explain the absence of survival improvement in our study.

10 First, the median number of lines of chemotherapy was similar and equal to three in

11 the two groups, which is higher than reported in the literature [20]. Second, we

12 observed similarities between the two major chemotherapeutic drugs used in MBC,

13 i.e. anthracyclines and taxanes, which were administered to the majority of patients

14 in the two groups. Thus taxanes were extensively used in both cohorts, all lines

15 included. Data showing improvement of OS with the use of taxanes in advanced

16 breast cancer came from trials comparing populations with exposure to taxanes to

17 those with limited exposure (limited cross-over)[23]. As a consequence, this fact does not allow entertaining any potential impact of taxanes on OS between the 2 cohorts. Third, the major difference between the two periods of time was the introduction of

20 trastuzumab and capecitabine. Trastuzumab was given only to the sub-group of 21 patients with positive HER-2 status, who represent no more than $25 \%$ of all MBC patients [24]. The benefit of this drug is expected to be limited to this population [25]. In our study, the sub-group of HER-2 positive patients treated with trastuzumab actually benefited from this drug since their survival was equal to that of patients with 
1 prognosis. These observations are in accordance with recent reports [26]. Thus,

2 trastuzumab has definitively an effect on OS of patients with positive HER-2 status,

3 but this beneficial impact is diluted in our study due to the small percentage of these

4 patients among total MBC population. Capecitabine has only a modest potential

5 benefit in terms of overall survival, as shown in the registration trial [27]. Moreover,

6 the compliance of patients to this oral agent is certainly an issue to be addressed in

7 the context of potential impact on OS.

8 Interestingly, we observed a trend toward improved survival over time in patients with

9 HR-positive tumors. This is probably related to the use of new hormonal therapies

10 approved for MBC patients during the last decade such as aromatase inhibitors [28]

11 and $\mathrm{LH}-\mathrm{RH}$ agonists combined with tamoxifen [29, 30]; these drugs have

12 demonstrated a significant survival benefit over other endocrine therapies.

13 Our study has many limitations. It is a retrospective study conducted in a tertiary care

14 institution with biases that do not allow drawing any general reliable conclusions on

15 the impact of modern chemotherapies and trastuzumab on survival of MBC patients.

16 The two cohorts are small and consequently lack statistical power. This small sample

17 size introduces some concerns in the context of an extremely heterogeneous

18 malignancy like breast carcinoma.

19 Our medico-economic study also has many limitations. First, we only evaluated the 20 costs of MBC chemotherapy drugs, and we did not explore other direct and indirect 21 costs, principally hospitalization costs which probably decreased with the extensive 22 use of outpatient hospitalization and the development of cancer supportive 23 treatments like biphosphonates and G-CSF. Indeed, 18\% of group 1 patients 24 received HDCSCT. In this case, the costs of chemotherapy drugs were clearly 25 negligible compared to the total costs of the procedure [31]. Second, we used 2008 
1 prices, not the prices in effect when the drugs were administered. As the prices of

2 certain drugs like taxanes and trastuzumab have changed over the last decade, this

3 could have an impact on the calculation of total costs. Third, we did not evaluate the

4 quality of life of the patients included in our cohort, because the study was 5 retrospective. Nevertheless, our results confirm the important increase over time of

6 expenditures related to chemotherapy drugs [32]. In MBC, the part of chemotherapy

7 in the total pharmaceutical costs has grown from $10 \%$ to $26 \%$ between 1988 and 82000 [33] and this evolution has probably accelerated since the approval of new

9 expensive targeted therapies such as trastuzumab, lapatinib and bevacizumab.

10 There is a growing consensus worldwide that cost-effectiveness considerations 11 should be taken into account when making private or public health insurance 12 decisions regarding the coverage of innovative and costly medical procedures [34]. 13 As the median survival of MBC patients does not exceed 3 years, a cost-utility study 14 evaluating both the costs of treatment and patient quality of life in a large prospective 15 and multicentric study, i.e. the French federation of cancer centers, with control of 16 major outcome predictors could be useful in order to draw the appropriate 17 conclusions. 


\section{Aknowledgements}

2 The authors acknowledge Mrs Marie-Dominique Reynaud for editorial assistance. 


\section{References}

2 1. Hortobagyi GN. Treatment of breast cancer. N Engl J Med 1998; 339: 974-984.

3 2. Wilcken N, Dear R. Chemotherapy in metastatic breast cancer: A summary of all randomised

4 trials reported 2000-2007. Eur J Cancer 2008; 44: 2218-2225.

5 3. Carrick S, Parker S, Thornton CE et al. Single agent versus combination chemotherapy for 6 metastatic breast cancer. Cochrane Database Syst Rev 2009; CD003372.

7 4. Priol G, Maurel F, Le Pen C. [Cost-effectiveness analysis of capecitabine in combination with 8 docetaxel in comparison to docetaxel monotherapy in advanced or metastatic breast cancer in France]. 9 Bull Cancer 2005; 92: 809-816.

10 5. Singletary SE, Allred C, Ashley P et al. Revision of the American Joint Committee on Cancer 11 staging system for breast cancer. J Clin Oncol 2002; 20: 3628-3636.

12 6. Kaplan EL MP. Nonparametric estimation from incomplete observations. J Am Stat Assoc 1958; $13 \quad 53: 457-481$.

14 7. DR C. Regression model and lifer tables (with discussion). JR Stat Soc 1972; 34: 187-220.

15 8. Biron P, Durand M, Roche $\mathrm{H}$ et al. Pegase 03: a prospective randomized phase III trial of FEC 16 with or without high-dose thiotepa, cyclophosphamide and autologous stem cell transplantation in first17 line treatment of metastatic breast cancer. Bone Marrow Transplant 2008; 41: 555-562.

18 9. Bachelot T, Gomez F, Biron $P$ et al. A phase I/II study of 4 monthly courses of high-dose 19 cyclophosphamide and thiotepa for metastatic breast cancer patients. Br J Cancer 2002; 87: 1079-1085.

20 10. Lotz JP, Cure H, Janvier $M$ et al. High-dose chemotherapy with haematopoietic stem cell 21 transplantation for metastatic breast cancer patients: final results of the French multicentric randomised CMA/PEGASE 04 protocol. Eur J Cancer 2005; 41: 71-80.

23 11. Randomized trial of two versus five years of adjuvant tamoxifen for postmenopausal early stage 24 breast cancer. Swedish Breast Cancer Cooperative Group. J Natl Cancer Inst 1996; 88: 1543-1549.

25 12. Tamoxifen for early breast cancer: an overview of the randomised trials. Early Breast Cancer 26 Trialists' Collaborative Group. Lancet 1998; 351: 1451-1467.

27 13. Matter-Walstra KW, Dedes KJ, Schwenkglenks $M$ et al. Trastuzumab beyond progression: a 28 cost-utility analysis. Ann Oncol 2010. 
14. Poncet B, Colin C, Bachelot $\mathbf{T}$ et al. Treatment of metastatic breast cancer: a large observational study on adherence to French prescribing guidelines and financial cost of the anti-HER2 antibody trastuzumab. Am J Clin Oncol 2009; 32: 369-374. 15. Perez-Ellis C, Goncalves A, Jacquemier J et al. Cost-Effectiveness Analysis of Trastuzumab (Herceptin) in HER2-Overexpressed Metastatic Breast Cancer. Am J Clin Oncol 2009. 16. Benedict A, Cameron DA, Corson H, Jones SE. An economic evaluation of docetaxel and paclitaxel regimens in metastatic breast cancer in the UK. Pharmacoeconomics 2009; 27: 847-859. 17. Paviot BT, Bachelot T, Clavreul G et al. [Impact of the chemotherapy protocols for metastatic breast cancer on the treatment cost and the survival time of 371 patients treated in three hospitals of the Rhone-Alpes region]. Bull Cancer 2009; 96: 929-940. 18. Affssaps. Les ventes de médicaments aux officines et aux hôpitaux en France Chiffres-clés 2006. 2007.

19. Chia SK, Speers CH, D'Yachkova Y et al. The impact of new chemotherapeutic and hormone agents on survival in a population-based cohort of women with metastatic breast cancer. Cancer 2007; 110: 973-979.

20. Andre F, Slimane K, Bachelot $\mathbf{T}$ et al. Breast cancer with synchronous metastases: trends in survival during a 14-year period. J Clin Oncol 2004; 22: 3302-3308.

21. Giordano SH, Buzdar AU, Smith TL et al. Is breast cancer survival improving? Cancer 2004; 100: 44-52.

22. P. Arveux PG, E. Reyrat, M. Velten, V. J. Bardou, L. Borella. . Breast cancer survival in France: A relative survival analysis based on 68,449 cases treated in the 20 French comprehensive cancer centers between 1980 and 1999. J Clin Oncol 2003; 22: Abstract 3437.

23. Nabholtz JM, Senn HJ, Bezwoda WR et al. Prospective randomized trial of docetaxel versus mitomycin plus vinblastine in patients with metastatic breast cancer progressing despite previous anthracycline-containing chemotherapy. 304 Study Group. J Clin Oncol 1999; 17: 1413-1424.

24. Owens MA, Horten BC, Da Silva MM. HER2 amplification ratios by fluorescence in situ hybridization and correlation with immunohistochemistry in a cohort of 6556 breast cancer tissues. Clin Breast Cancer 2004; 5: 63-69.

25. Slamon DJ, Leyland-Jones B, Shak S et al. Use of chemotherapy plus a monoclonal antibody 
1 26. Dawood S, Broglio K, Buzdar AU et al. Prognosis of women with metastatic breast cancer by

2 HER2 status and trastuzumab treatment: an institutional-based review. J Clin Oncol 2010; 28 : $92-98$.

3 27. Seidman AD, O'Shaughnessy J, Misset JL. Single-agent capecitabine: a reference treatment for 4 taxane-pretreated metastatic breast cancer? Oncologist 2002; 7 Suppl 6: 20-28.

5 28. Gibson L, Lawrence D, Dawson C, Bliss J. Aromatase inhibitors for treatment of advanced breast 6 cancer in postmenopausal women. Cochrane Database Syst Rev 2009; CD003370.

7 29. Klijn JG, Beex LV, Mauriac $\mathrm{L}$ et al. Combined treatment with buserelin and tamoxifen in 8 premenopausal metastatic breast cancer: a randomized study. J Natl Cancer Inst 2000; 92: 903-911.

9 30. Klijn JG, Blamey RW, Boccardo F et al. Combined tamoxifen and luteinizing hormone-releasing hormone (LHRH) agonist versus LHRH agonist alone in premenopausal advanced breast cancer: a metaanalysis of four randomized trials. J Clin Oncol 2001; 19: 343-353.

12 31. De Rosa L, Lalle M, Pandolfi A, Pescador L. Costs of high-dose chemotherapy and peripheral 13 blood progenitor cell autograft for breast cancer. Bone Marrow Transplant 2001; 27: 1031-1035.

14 32. Halbert RJ, Zaher $\mathbf{C}$, Wade $\mathbf{S}$ et al. Outpatient cancer drug costs: changes, drivers, and the future. Cancer 2002; 94: 1142-1150.

16 33. Levy C, Bonastre J. [The cost of chemotherapy]. Bull Cancer 2003; 90: 976-982. 34. Garber AM. Cost-effectiveness and evidence evaluation as criteria for coverage policy. Health Aff (Millwood) 2004; Suppl Web Exclusives: W4-284-296. 
1 Tables and Figures

2

3 Table 1: Baseline demographics of the two time groups. SCT: stem cell

4 transplantation

5 Table 2: Lines of chemotherapy (LOC) administered in the metastatic setting

6 Table 3: Univariate analysis of overall survival (OS). Cl: Confidence Interval, HR:

7 Hazard Ratio, SBR: Scarff Bloom and Richardson score.

8 Table 4: Multivariate analysis of overall survival adjusted to the group of

9 patients. HR: Hazard Ratio; $95 \% \mathrm{Cl}: 95 \%$ Confidence Interval

10 Table 5: Costs of lines of chemotherapy according to patient group.*: patient

11 included in a clinical trial

12 Table 6: Costs of the three most expensive chemotherapy drugs according to

13 patient group.

14 Figure 1: Overall survival of metastatic breast cancer patients according to the 15 period of treatment.

16 Figure 2: Overall survival of metastatic breast cancer patients according to

17 HER-2 status.

18 Figure 3: Overall survival of metastatic breast cancer patients with positive 19 hormone receptors according to the group. 
Group 1 (1994-1998) Group 2 (2003-2006) $\quad P$

\begin{tabular}{llllll} 
& & $\mathbf{n = 1 4 9}$ & $\mathbf{n = 1 5 2}$ & \\
\hline $\begin{array}{l}\text { Median age at diagnosis of MBC, years } \\
\leq 50\end{array}$ & 49 & & 55 & & \\
$>50$ & 62 & $(55 \%)$ & 51 & $(35.6 \%)$ & $<0.001$ \\
& 67 & $(67 \%)$ & 101 & $(66.5 \%)$ & \\
\hline Median disease-free interval, years & & & & & \\
$\leq 2$ & 67 & $(45 \%)$ & 70 & $(46 \%)$ & NS \\
$>2$ & 82 & $(55 \%)$ & 82 & $(54 \%)$ &
\end{tabular}

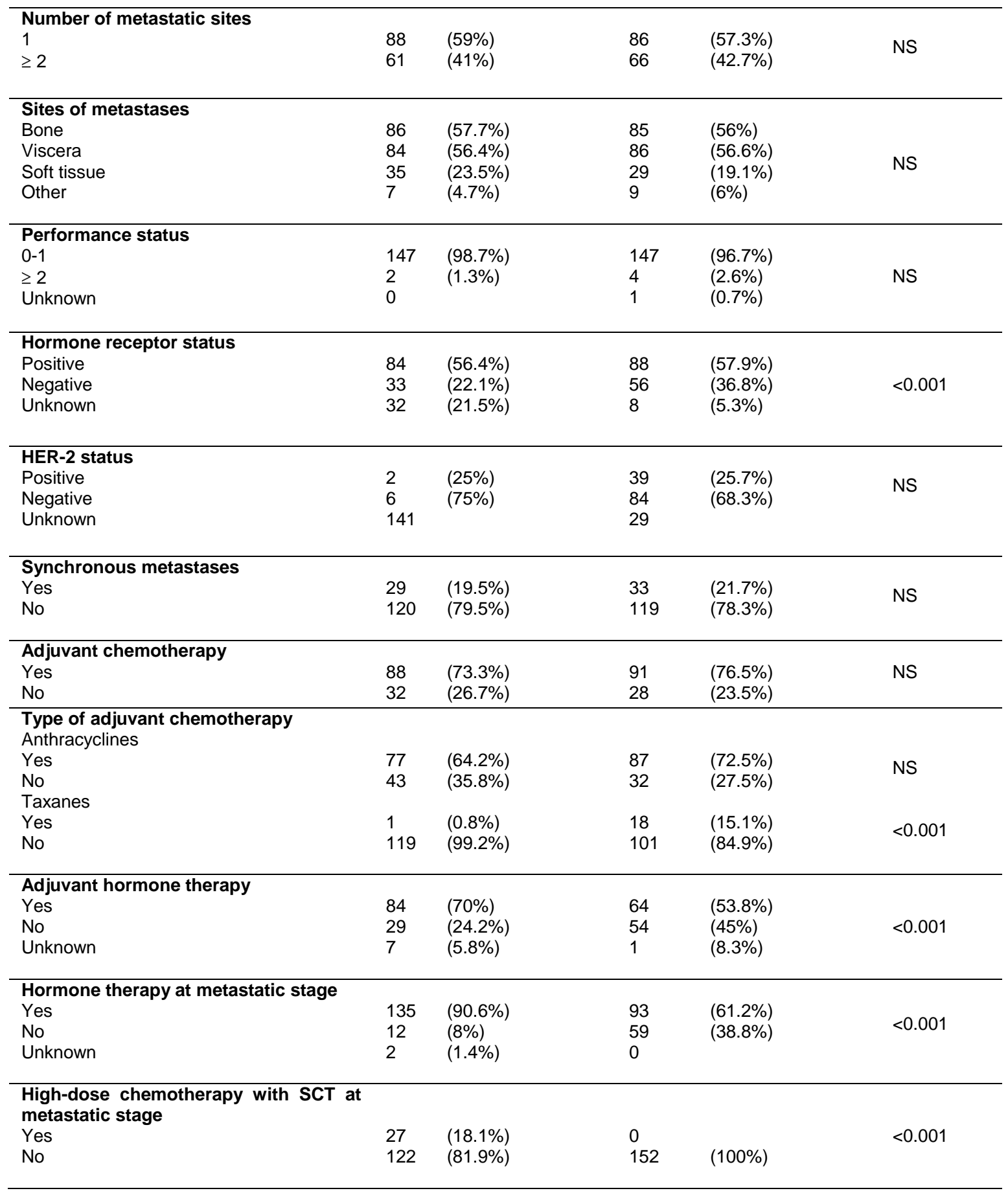

\section{Table 1}

3 


\begin{tabular}{|c|c|c|c|}
\hline & $\begin{array}{l}\text { Group 1(1994-1998) } \\
\text { n }\end{array}$ & $\begin{array}{l}\text { Group } 2 \text { (2003-2006) } \\
\text { n }\end{array}$ & $P$ \\
\hline $\begin{array}{l}\text { Number of LOC } \\
\text { Median } \\
\text { Minimum } \\
\text { Maximum }\end{array}$ & $\begin{array}{l}3 \\
1 \\
11\end{array}$ & $\begin{array}{l}3 \\
1 \\
11\end{array}$ & NS \\
\hline $\begin{array}{l}\text { Anthracyclines } \\
1^{\text {st }} \text { line } \\
\text { All lines }\end{array}$ & $\begin{array}{l}115(77.2 \%) \\
139(93.3 \%)\end{array}$ & $\begin{array}{l}52(34.2 \%) \\
76(50 \%)\end{array}$ & $\begin{array}{l}<0.001 \\
<0.001\end{array}$ \\
\hline $\begin{array}{l}\text { Taxanes } \\
1^{\text {st }} \text { line } \\
\text { All lines }\end{array}$ & $\begin{array}{l}25(16.8 \%) \\
107(71.8 \%)\end{array}$ & $\begin{array}{l}103(67.8 \%) \\
129(84.9 \%)\end{array}$ & $\begin{array}{l}<0.001 \\
<0.01\end{array}$ \\
\hline $\begin{array}{l}\text { Capecitabine } \\
1^{\text {st }} \text { line } \\
\text { All lines }\end{array}$ & $\begin{array}{l}0 \\
7(4.7 \%)\end{array}$ & $\begin{array}{l}26(17.1 \%) \\
105(69 \%)\end{array}$ & $\begin{array}{l}<0.001 \\
<0.001\end{array}$ \\
\hline $\begin{array}{l}\text { Vinorelbine } \\
1^{\text {st }} \text { line } \\
\text { All lines }\end{array}$ & $\begin{array}{l}14(9.4 \%) \\
112(75.2 \%)\end{array}$ & $\begin{array}{l}7(4.6 \%) \\
84(55.3 \%)\end{array}$ & $\begin{array}{l}\text { NS } \\
<0.001\end{array}$ \\
\hline $\begin{array}{l}\text { Trastuzumab } \\
1^{\text {st }} \text { line } \\
\text { All lines }\end{array}$ & $\begin{array}{l}0 \\
3(100 \% \text { of HER- } 2+)\end{array}$ & $\begin{array}{l}32(21 \%) \\
38(100 \% \text { of HER- } 2+)\end{array}$ & $\begin{array}{l}<0.001 \\
\text { NS }\end{array}$ \\
\hline
\end{tabular}

2

3 Table 2

4 


\begin{tabular}{|c|c|c|c|c|}
\hline \multirow[b]{2}{*}{ Variable } & \multicolumn{4}{|c|}{ OS adjusted on group of patients } \\
\hline & $\mathbf{n}$ & HR & $95 \% \mathrm{Cl}$ & $P$ \\
\hline \multicolumn{5}{|c|}{ Primary tumor size } \\
\hline T1 & 70 & 1 & - & \\
\hline$\geq \mathrm{T} 2$ & 133 & 1.25 & $0.97-1.61$ & 0.09 \\
\hline \multicolumn{5}{|c|}{ SBR grade } \\
\hline 1 & 13 & 1 & - & \\
\hline 2 & 104 & 1.23 & $0.64-2.38$ & \\
\hline 3 & 103 & 1.64 & $0.85-3.15$ & 0.10 \\
\hline \multicolumn{5}{|c|}{ Number of involved nodes } \\
\hline 0 & 67 & 1 & - & \\
\hline$\geq 1$ & 182 & 0.95 & $0.70-1.28$ & 0.72 \\
\hline \multicolumn{5}{|c|}{ Hormone receptors } \\
\hline No & 89 & 1 & - & \\
\hline Yes & 172 & 0.55 & $0.42-0.73$ & $<0.0001$ \\
\hline \multicolumn{5}{|c|}{ HER-2 expression } \\
\hline No & 90 & 1 & - & \\
\hline Yes & 41 & 0.99 & $0.64-1.55$ & 0.99 \\
\hline \multicolumn{5}{|c|}{ Adjuvant chemotherapy } \\
\hline No & 57 & 1 & - & \\
\hline Yes & 179 & 1.02 & $0.75-1.40$ & 0.89 \\
\hline \multicolumn{5}{|c|}{ Adjuvant hormone therapy } \\
\hline No & 83 & 1 & - & \\
\hline Yes & 148 & 0.77 & $0.57-1.03$ & 0.08 \\
\hline \multicolumn{5}{|c|}{ Adjuvant radiotherapy } \\
\hline No & 19 & 1 & - & \\
\hline Yes & 213 & 0.97 & $0.58-1.63$ & 0.91 \\
\hline \multicolumn{5}{|c|}{ Age at diagnosis of metastases } \\
\hline$\leq 50$ & 133 & 1 & - & \\
\hline$>50$ & 168 & 0.85 & $0.66-1.09$ & 0.20 \\
\hline \multicolumn{5}{|c|}{ Progression-free interval } \\
\hline$\leq 2$ years & 137 & 1 & - & \\
\hline$>2$ years & 164 & 0.78 & $0.61-0.99$ & 0.04 \\
\hline \multicolumn{5}{|c|}{ Number of metastatic sites } \\
\hline 1 & 174 & 1 & - & \\
\hline$\geq 2$ & 125 & 1.74 & $1.36-2.24$ & $<0.0001$ \\
\hline \multicolumn{5}{|c|}{ Bone metastases } \\
\hline No & 130 & 1 & - & \\
\hline Yes & 171 & 0.76 & $0.59-0.97$ & 0.03 \\
\hline \multicolumn{5}{|c|}{ Soft tissue metastases } \\
\hline No & 237 & 1 & - & \\
\hline Yes & 64 & 1.64 & $1.22-2.21$ & 0.001 \\
\hline \multicolumn{5}{|c|}{ Visceral metastases } \\
\hline No & 131 & 1 & - & \\
\hline Yes & 170 & 1.56 & $1.21-2.00$ & 0.0001 \\
\hline
\end{tabular}

Performance status

0-1

294 


$\begin{array}{lrlll}>1 & 6 & 3.55 & 1.45-8.66 & 0.006 \\ \mathbf{1}^{\text {st }} \quad \text { line chemotherapy } & \text { with } & & & \\ \text { anthracyclines } & & & & \\ \text { No } & 128 & 1 & - & 0.02 \\ \text { Yes } & 172 & 0.72 & 0.55-0.94 & \\ \mathbf{1}^{\text {st line chemotherapy }} \text { with } & & & \\ \text { taxanes } & 173 & 1 & - & \\ \text { No } & 128 & 0.99 & 0.73-1.35 & 0.95 \\ \text { Yes } & & & \end{array}$

\section{Table 3}

2 
2

\begin{tabular}{|l|l|l|l|}
\hline Variables & HR & $\mathbf{9 5 \%}$ Cl & $\boldsymbol{P}$ \\
\hline Single metastatic site & 0.48 & $0.36-0.64$ & $<0.0001$ \\
\hline Bone metastases & 0.67 & $0.50-0.90$ & 0.007 \\
\hline Positive hormone receptors & 0.56 & $0.42-0.77$ & 0.0002 \\
\hline Group & 1.04 & $0.70-1.55$ & 0.83 \\
\hline
\end{tabular}

3

$4 \quad$ Table 4

5

6 
1

\begin{tabular}{|c|c|c|c|c|c|c|c|}
\hline & \multicolumn{3}{|c|}{$\begin{array}{l}\text { Group } 1 \text { (1994-1998) } \\
\qquad(\mathrm{n}=149)\end{array}$} & \multicolumn{3}{|c|}{$\begin{array}{c}\text { Group } 2 \text { (2003-2006) } \\
(\mathrm{n}=152)\end{array}$} & \multirow[b]{2}{*}{$p$} \\
\hline & Median & Minimum & Maximum & Median & Minimum & Maximum & \\
\hline $\begin{array}{lr}\text { Total cost } & \text { of } \\
\text { chemotherapy drugs } \\
\text { per patient }(€)\end{array}$ & 6,272 & 20 & 189,923 & 13,035 & 11 & 162,960 & $<0.001$ \\
\hline Cost of $1^{\text {st }}$ line $(€)$ & 1,269 & 1.50 & 12,994 & 5,744 & 11 & 137,074 & $<0.001$ \\
\hline Cost of $2^{\text {nd }}$ line $(€)$ & 1,421 & $0^{*}$ & 18,900 & 2,625 & $0^{*}$ & 53,564 & $<0.001$ \\
\hline Cost of $3^{\text {rd }}$ line $(€)$ & 1,074 & 0.40 & 14,484 & 2,315 & $0^{*}$ & 30,509 & $<0.001$ \\
\hline
\end{tabular}

3

\section{$4 \quad$ Table 5}

5 


\begin{tabular}{|l|c|c|c|c|c|c|}
\hline & \multicolumn{3}{|c|}{ Group 1 (1994-1998) } & \multicolumn{3}{c|}{ Group 2 (2003-2006) } \\
\hline & $\begin{array}{c}\text { Number of } \\
\text { patients } \\
(\%)\end{array}$ & Total costs (€) & $\%$ of costs & $\begin{array}{c}\text { Number of } \\
\text { patients } \\
(\%)\end{array}$ & Total costs (€) & \% of costs \\
& $3(2 \%)$ & 153,037 & 11.6 & $40(26.3 \%)$ & $1,726,970$ & 44.8 \\
\hline Trastuzumab & $94(63 \%)$ & 623,840 & 47.2 & $89(58.6 \%)$ & 569,546 & 14.7 \\
\hline Docetaxel & $22(14.7 \%)$ & 103,891 & 7.8 & $72(47.4 \%)$ & 298,273 & 7.7 \\
\hline Paclitaxel & & & & & & \\
\hline
\end{tabular}

2

\section{Table 6}

4 
Figure 1

Click here to download Figure: figure 1.ppt

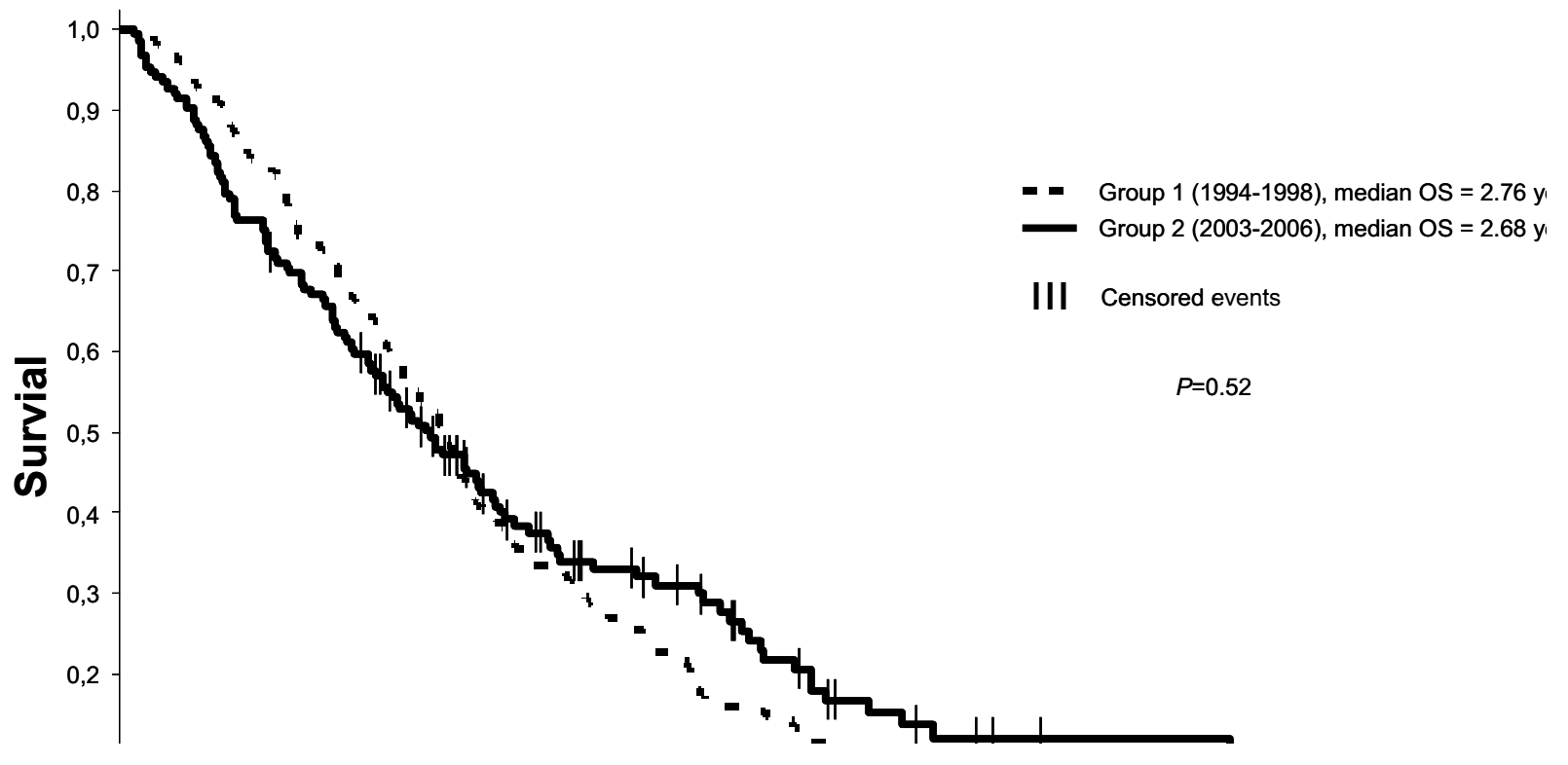


Figure 2

Click here to download Figure: figure 2.ppt

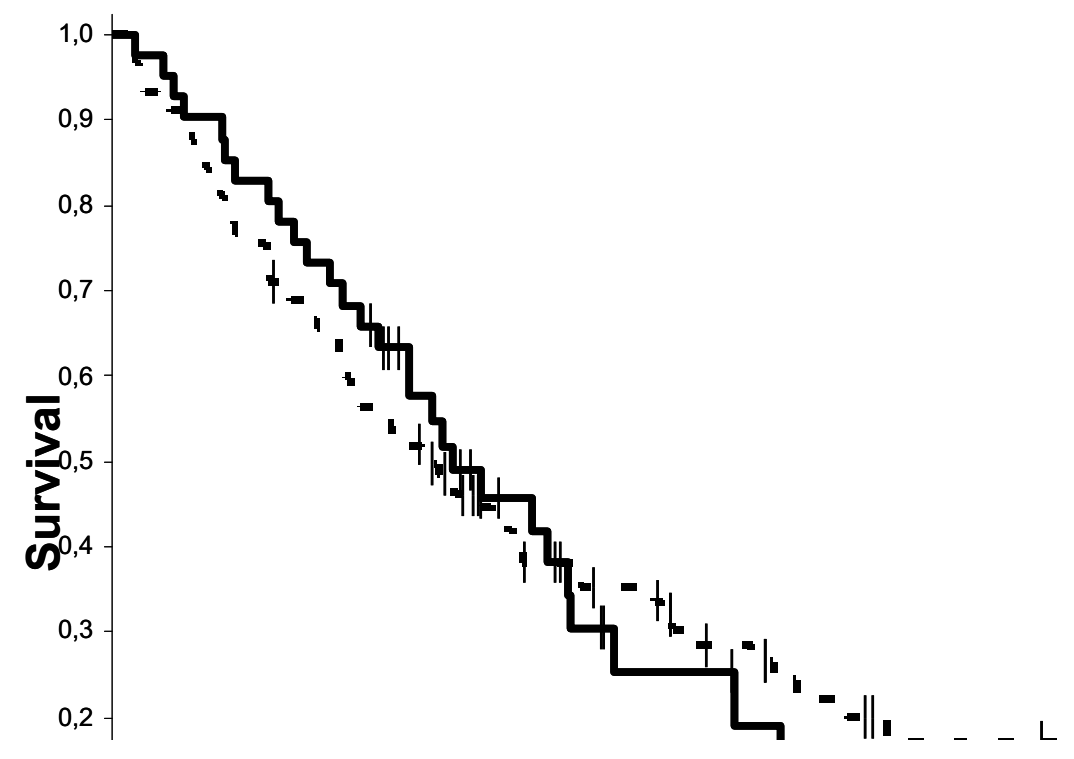$$
\begin{array}{r}
\text { - HER- } \\
\text { HER 2+ }
\end{array}
$$

$P=0.99$ 


\section{Figure 3}

Click here to download Figure: figure 3.ppt

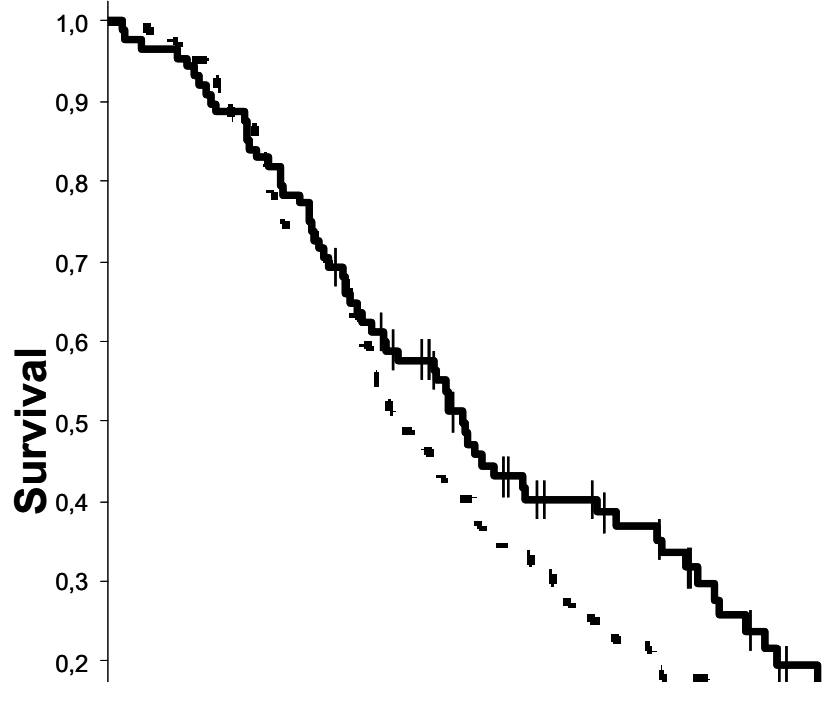

- - Group 1 (1994-1998), median OS $=2.54$ years

Group $2(2003-2006)$, median OS $=3.15$ years

III Censored events

$P=0.13$ 